\title{
Colloids and Interfaces
}

\author{
Reinhard Miller
}

Department of Biomaterials, Max Planck Institute of Colloids and Interfaces, Potsdam-Golm Science Park, Am Mühlenberg 1, 14476 Potsdam, Germany; Reinhard.Miller@mpikg.mpg.de; Tel.: +49-331-5679252

Received: 7 December 2017; Accepted: 11 December 2017; Published: 12 December 2017

Colloids and Interfaces is a new, online, open access journal published by MDPI. It aims at publishing manuscripts for all aspects of colloid and interfaces science. The journal provides an interdisciplinary forum for experimental and theoretical work, dedicated to fundamental as well as applied science. This spans experimental methodologies to various types of simulations.

The broad range of topics include interfacial phenomena, including surface tension measurements, interfacial rheology studies, and measurements of interfacial properties using linear and non-linear optical techniques. The behavior of solutions (micellar solutions and micro-emulsions) and colloidal systems will be described by the application of a multitude of experimental techniques, including light scattering, rheology, spectroscopy, microscopy, scattering, and reflection techniques, as well as many other methodologies.

The journal will also deal with specific problems of liquid disperse systems, such as foams and emulsions and their building blocks, liquid thin films. This includes particular experimental techniques as well as theoretical approaches for the formation and stability of disperse systems.

Materials investigated as modifying agents of surface and/or bulk properties are surfactants, polymers, proteins, (nano)-particles, and their mixtures.

We seek manuscripts dedicated to fundamental research but also applied science and technology in the fields of chemistry, cosmetics, materials science and chemical engineering, polymer science, food technology, pharmacy, and petrochemical systems. The journal is also open to new directions in colloid and interface science.

The main type of contributions will obviously be original papers, which must not be published elsewhere, even in parts. In addition, review articles are welcome giving overviews of up to date topics, although, simple literature searches via Web of Science or similar data pools are not acceptable.

The journal is also dedicated to publishing special issues for conferences or themed issues on hot topics or themes that have made significant recent progress.

The members of the Editorial Board are experts in the various scientific fields covered by our journal. The members will provide their expertise to evaluate the quality of submitted manuscripts in addition to being responsible for editing special/themed issues. Authors can address the Editor and the Board Members to propose ideas to maintain and improve the quality of this journal.

All manuscripts submitted to Colloids and Interfaces will be peer-reviewed by experts in the field and eventually, if accepted by an independent academic editor, published online in Open Access. Open access provides several advantages, including rapid publication online, free access on the web to anyone, and the published material, including text and figures, can be re-used to build new projects and innovations provided that the original work is properly cited.

(C) 2017 by the author. Licensee MDPI, Basel, Switzerland. This article is an open access article distributed under the terms and conditions of the Creative Commons Attribution (CC BY) license (http:/ / creativecommons.org/licenses/by/4.0/). 